Chronic Obstructive Pulmonary Diseases:

Journal of the COPD Foundation

Images in COPD

\title{
Images in COPD: Idiopathic Emphysema in a Never Smoker
}

\author{
Stephan S. Leung, $\mathrm{MD}^{1}$ Patrick Lee, $\mathrm{MD}^{1}$ Jessica E. Most, $\mathrm{MD}^{2}$ Baskaran Sundaram, $\mathrm{MD}^{1}$
}

Abbreviations: chronic obstructive pulmonary disease, COPD; alpha-1-antitrypsin deficiency, AATD; human immunodeficiency virus, HIV; hypocomplementemic urticarial vasculitis syndrome, HUVS; alpha-1-antitrypsin protein, AAT; erythrocyte sedimentation rate, ESR; forced expiratory volume per 1 second, FEV $\mathbf{1}$; forced vital capacity, FVC; total lung capacity, TLC; residual volume, RV Funding Support: not applicable

Citation: Leung SS, Lee P, Most JE, Sundaram B. Images in COPD: idiopathic emphysema in a never smoker. Chronic Obstr Pulm Dis. 2020;7(2):130-133. doi: https://doi.org/10.15326/jcopdf.7.2.2020.0148

1 Division of Cardiothoracic Radiology, Department of Radiology, Thomas Jefferson University Hospital, Philadelphia, Pennsylvania 2 Division of Pulmonology, Department of Medicine, Thomas Jefferson University Hospital, Philadelphia, Pennsylvania

\section{Keywords:}

emphysema; idiopathic

\section{Address correspondence to:}

Baskaran Sundaram, MD

Division of Cardiothoracic Radiology

Department of Radiology

Thomas Jefferson University Hospital

Philadelphia, Pennsylvania

Email: baskaran.sundaram@jefferson.edu

Telephone: (215) 955-4214

Fax: (215) 955-549

\section{Introduction}

Smoking is an important risk factor for the development of chronic obstructive pulmonary disease (COPD). This risk includes exposure to secondhand smoking. However, it is estimated that $10 \%$ of patients with emphysema have either rarely or never smoked. ${ }^{1}$ In this population, depending on the clinical picture, further consideration should be given to other potential causes for emphysema such as idiopathic, alpha-1-antitrypsin deficiency (AATD), heritable connective tissue disorders, intravenous drug abuse, human immunodeficiency virus (HIV), hypocomplementemic urticarial vasculitis syndrome (HUVS), and environmental exposures.

\section{Case History}

"G.S" a 73-year-old male with no history of smoking or exposure to secondhand smoke presented for evaluation of increasing limitation of physical activity with shortness of breath. At this time, he was diagnosed with asthma-COPD overlap syndrome. He was medically managed with inhaled corticosteroids and a long-acting beta2-agonist. He denied a history of intravenous drug abuse. Blood work revealed an alpha-1-antitrypsin protein (AAT) level of $141 \mathrm{mg} / \mathrm{dL}$ (normal $101-187 \mathrm{mg} / \mathrm{dL}$ ). Erythrocyte sedimentation rate (ESR) was $2 \mathrm{~mm} / \mathrm{hr}$ (normal $0-30 \mathrm{~mm} / \mathrm{hr}$ ). C1q complement levels were $15.0 \mathrm{mg} / \mathrm{dL}$ (normal 11.8 $23.8 \mathrm{mg} / \mathrm{dL}$ ).

\section{Imaging}

Here are the images taken of patient G.S., along with spirometry results. (Figures 1, 2, and 3). 
Figure 1. Chest Radiographs
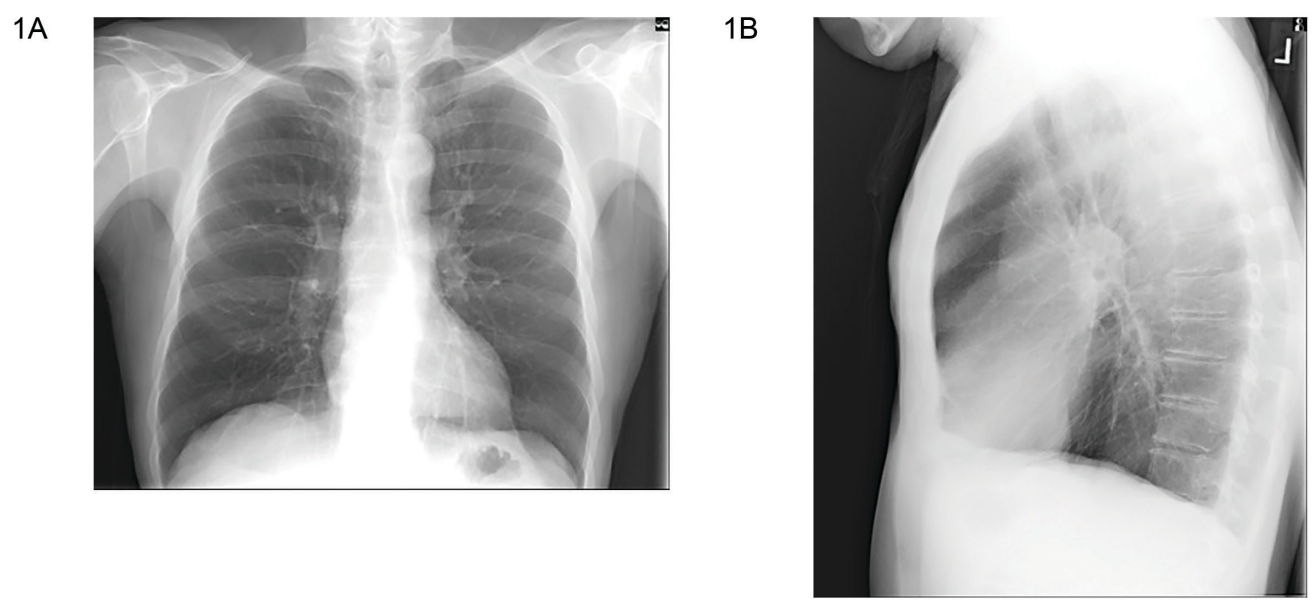

Posteroanterior (A) and lateral (B) radiographs of the chest dated 9/22/2015 showing changes of emphysema. There is lung hyperinflation with flattening of both hemidiaphragms as seen on the lateral radiograph. The retrosternal airspace is increased and there is increased lucency of the lungs bilaterally.

\section{Figure 2. Spirometry Curve Results}

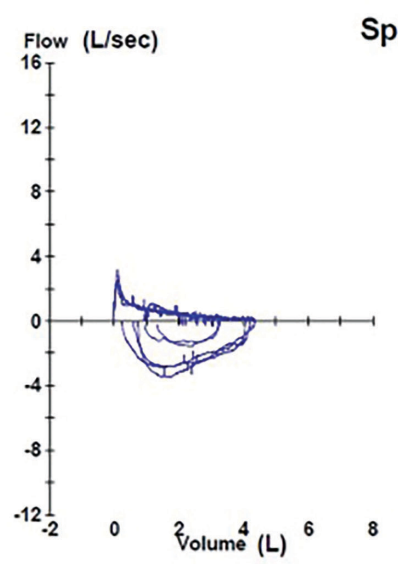

Spirometry Pre Post

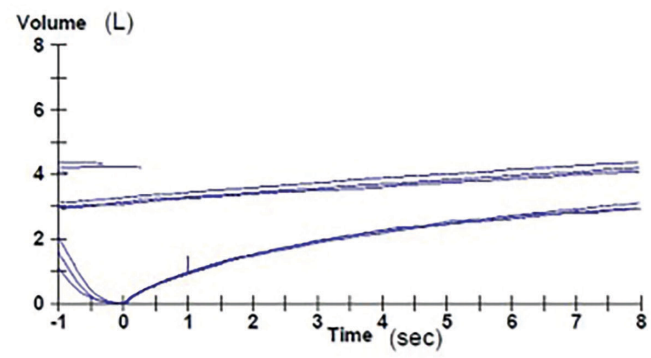

(L/s)

(L)

Spirometry curve results most recently from 10/25/2019. $\mathrm{FEV}_{1}$ of $0.98 \mathrm{~L}$ (33\% of predicted), FVC of $4.37 \mathrm{~L}$ (110\% of predicted) and $\mathrm{FEV}_{1} / \mathrm{FVC}$ ratio of 0.22 . Most recent measurements of lung volumes by plethysmography revealed a TLC of $8.41 \mathrm{~L}(120 \%$ of predicted), a RV of $3.53 \mathrm{~L}$ (133\% of predicted), and a RV/TLC ratio of 0.42 . Diffusion capacity of carbon monoxide was $9.2 \mathrm{~mL} / \mathrm{min} / \mathrm{mmHg}(37 \%$ of predicted).

$\mathrm{FEV}_{1}=$ forced expiratory volume in 1 second; $\mathrm{FVC}=$ forced vital capacity; TLC=total lung capacity; $\mathrm{RV}=$ residual volume

\section{Figure 3. Computed Tomography Axial Images}
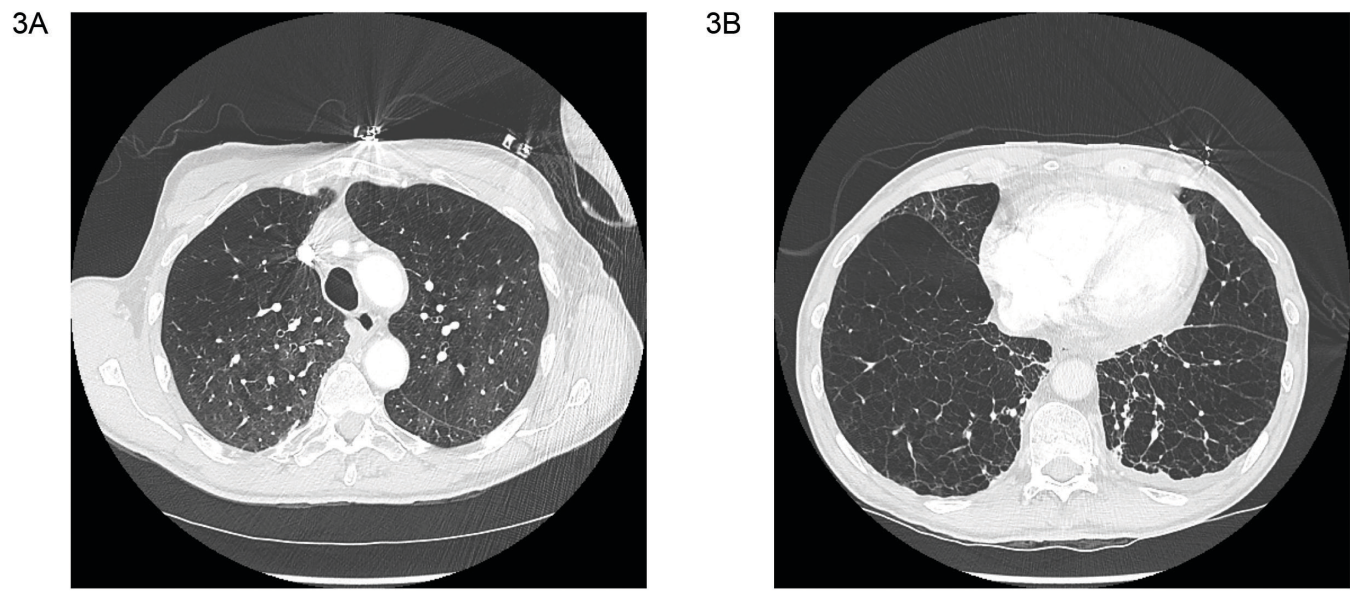

Computed tomography axial images dated 1/18/2019 through the upper (A) and lower (B) chest. There is panlobular emphysema with a lower lobe predominance in both lung fields.

For personal use only. Permission required for all other uses. 


\section{Discussion}

This clinical presentation highlights a case of severe emphysema in a nonsmoker. While smoking remains the de facto risk factor for the development of emphysema, in a never smoker patient, other potential etiologies should be considered.

It is estimated that AAT accounts for approximately $3 \%$ of cases of emphysema. ${ }^{2}$ The rate of decreased lung function is strongly affected by cigarette smoking in AAT patients. Radiological evidence of emphysema is more prevalent in smokers (approximately 90\%) than non-smokers (approximately 65\%). ${ }^{3}$ AAT should be suspected if the patient presents with emphysema at a young age ( $<45$ years old), the emphysema is in a nonsmoker, the emphysema is in a radiographical basilar predominant pattern, there is adult onset asthma or there is a family history of lung and liver disease (Figure 4). ${ }^{4}$ Diagnosis is confirmed with a serum AAT level $<57 \mathrm{mg} / \mathrm{dL}$ along with genetic confirmation.

Heritable connective tissue disorders are a heterogenous group of diseases which include Marfan syndrome, Ehlers-Danlos syndrome, and Cutis Laxa. Structural changes from gene mutations which affect tissue elasticity may predispose to the development of emphysema. ${ }^{5-7}$

Intravenous drug use has been associated with early onset development of emphysema. Talc, or hydrated magnesium silicate, is used in oral tablets such as methylphenidate and phenmetrazine to hold the components of the medication together. Injected talc can migrate to the lungs causing a granulomatous foreign-body reaction, which can continue to tissue destruction leading to apical bullous emphysematous changes. ${ }^{8}$

The relationship between HIV status and emphysema was first described in the 1980s. In contrast to smokingassociated emphysema, which clinically occurs over decades, HIV-associated emphysema develops over a period of years. $^{9}$

HUVS is a rare disorder that is typically characterized by urticarial lesions, decreased complement levels, and vasculitis. ${ }^{10}$ Emphysema in HUVS has been thought to be secondary to vasculitis of the lung resulting in pulmonary damage. Computed tomography typically shows bibasilar panacinar emphysema with bullous changes, air trapping, scattered ground-glass opacities, and minimal fibrotic and inflammatory changes at the lung bases. An elevated ESR and decreased serum complement levels lead to a diagnosis of HUVS.

A variety of environmental factors, particularly from occupational or agricultural exposures, have been studied as possible causes of emphysema. Although classically associated with lung fibrosis, some studies have suggested that these patients may be at higher risk for developing emphysema. ${ }^{11,12}$

\section{Declaration of Interest}

The authors have no conflicts of interest to declare.

\section{Figure 4. Computed Tomography Axial and Coronal (B) Representative Slices Through the Chest}

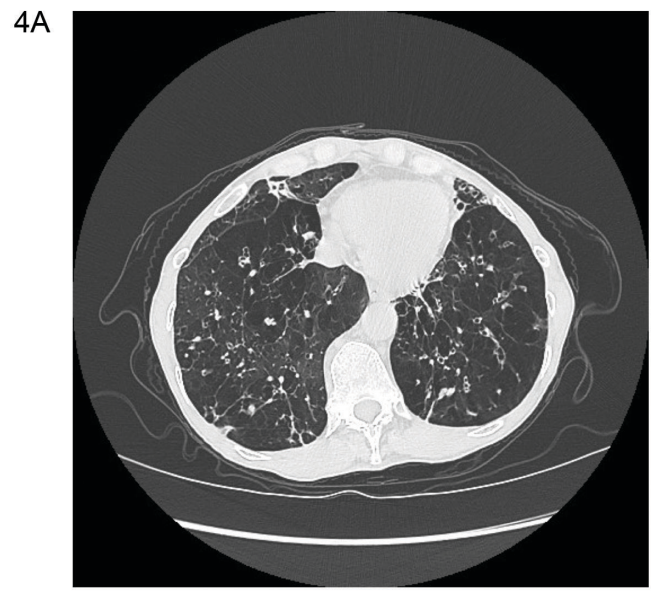

$4 \mathrm{~B}$

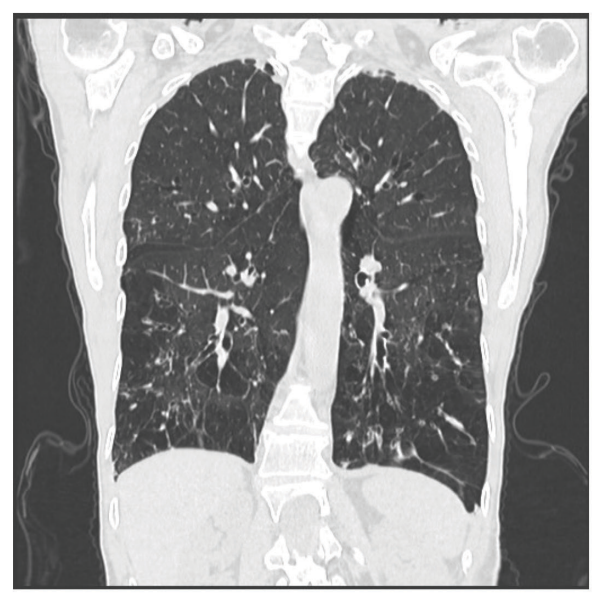

Computed tomography axial (A) and coronal (B) representative slices through the chest shows basal predominant panlobular emphysema throughout the lungs in a never smoker patient with AATD (ATT level $<20 \mathrm{mg} / \mathrm{dL}$ ). 


\section{References}

1. Fabro DS, Frenia DS. Emphysema in the nonsmoker. Clin Pulm Med. 2008;15(1):1-7.

doi: https://doi.org/10.1097/CPM.0b013e31816085a6

2. Lee P, Gildea TR, Stoller JK. Emphysema in nonsmokers: alpha 1-antitrypsin deficiency and other causes. Cleve Clin J Med. 2002;69(12):928-946. doi: https://doi.org/10.3949/ccjm.69.12.928

3. Tobin MJ, Cook PJ, Hutchison DC. Alpha 1 antitrypsin deficiency: the clinical and physiological features of pulmonary emphysema in subjects homozygous for Pi type Z. A survey by the British Thoracic Association. Br J Dis Chest. 1983;77(1):1427. doi: https://doi.org/10.1016/0007-0971(83)90002-5

4. Miravitlles M, Dirksen A, Ferrarotti I, et al. European Respiratory Society statement: diagnosis and treatment of pulmonary disease in a1-antitrypsin deficiency. Eur Respir J. 2017;50(5).

doi: https://doi.org/10.1183/13993003.00610-2017

5. Jessurun CAC, Bom DAM, Franken R. An update on the pathophysiology, treatment and genetics of Marfan syndrome. Expert Opin Orphan Drugs. 2016;4(6):605-612. doi: https://doi.org/10.1080/21678707.2016.1184083

6. Beridze N, Frishman WH. Vascular Ehlers-Danlos syndrome: pathophysiology, diagnosis, and prevention and treatment of its complications. Cardiol Rev. 2012;20(1):4-7.

doi: https://doi.org/10.1097/CRD.0b013e3182342316

7. Berk DR, Bentley DD, Bayliss SJ, Lind A, Urban Z. Cutis laxa: a review. J Am Acad Dermatol. 2012;66(5):842.

doi: https://doi.org/10.1016/j.jaad.2011.01.004

8. Roberts WC. Pulmonary talc granulomas, pulmonary fibrosis, and pulmonary hypertension resulting from intravenous injection of talc-containing drugs intended for oral use. Proc (Bayl Univ Med Cent). 2002;15(3):260-261.

doi: https://doi.org/10.1080/08998280.2002.11927851

9. Kuhlman JE, Knowles MC, Fishman EK, Siegelman SS. Premature bullous pulmonary damage in AIDS: CT diagnosis. Radiology. 1989;173(1):23-26.

doi: https://doi.org/10.1148/radiology.173.1.2781013

10. WisnieskiJJ,BaerAN, ChristensenJ,etal.Hypocomplementemic urticarial vasculitis syndrome. Clinical and serologic findings in 18 patients. Medicine (Baltimore). 1995;74(1):24-41. doi: https://doi.org/10.1097/00005792-199501000-00003

11. Erkinjuntti-Pekkanen R, Rytkonen H, Kokkarinen JI, Tukiainen HO, Partanen K, Terho EO. Long-term risk of emphysema in patients with farmer's lung and matched control farmers. Am J Respir Crit Care Med. 1998;158(2):662-665.

doi: https://doi.org/10.1164/ajrccm.158.2.9710012

12. Daniil Z, Koutsokera A, Gourgoulianis K. Combined pulmonary fibrosis and emphysema in patients exposed to agrochemical compounds. Eur Respir J. 2006;27(2):434.

doi: https://doi.org/10.1183/09031936.06.00124505

For personal use only. Permission required for all other uses. 